\title{
La casa venduta, de Federigo Tozzi
}

\author{
Maria Gloria Cusumano Mazzi
}

Federigo Tozzi nasceu em Siena, Região da Toscana, Itália, em $1^{\text {o }}$ de janeiro de 1883 e morreu em 21 de março de 1920, em Roma. Extremamente tímido e inseguro, filho único de pai autoritário com o qual conviveu em constante conflito, Tozzi sofreu profundamente a morte da mãe, epilética, que o deixou quando o escritor tinha 12 anos. As experiências autobiográficas estão muito presentes em todo o corpus tozziano, não tanto como triunfo da realidade e da sinceridade, quanto como sólido substrato para a construção de suas narrativas projetadas para além do realismo ou satisfação memorialística. Tozzi foi autor de ensaios, poesias, dramas, contos e cinco romances: Ricordi di un impiegato (1910), Con gli occhi chiusi (1913), Gli Egoisti (1900), Il Podere (1900) e Tre Croci (1900). Precursor do expressionismo italiano, Tozzi apresenta uma literatura do fragmento. Sua poética consiste em ver o homem fragmentado e incapaz de usar a palavra para se exprimir. Daí seu texto apresentar-se com uma pontuação fora da norma gramatical. O estilo e a forma dão sentido ao conteúdo. Na presente tradução, procurei manter ao máximo o ritmo original que, ao leitor desavisado, pode parecer erro gramatical. Decidi traduzir os nomes (non-portrait) de alguns personagens como Piombo-Chumbo, Achille-Aquiles pelo efeito de sentido que ambos criam na narrativa.

Neste esplêndido conto, "A casa vendida", o atônito protagonista Torquato, obrigado a vender a própria casa, já totalmente hi- 
Maria Gloria Cusumano Mazzi. La casa venduta, de Federigo Tozzi

potecada, é praticamente trucidado pelos três terríveis compradores que o humilham sem dó nem piedade, desvalorizando o imóvel e as poucas coisas que há nele. Com uma bestial indiferença, derrubam as fotografias da parede, caras lembranças da irmã e da mãe falecidas.

Enfim, sem outra alternativa, Torquato vende sua casa pelo valor da hipoteca e, à tarde, refugia-se da chuva embaixo do beiral da casa vendida, ouvindo o som de uma música tocada por um de seus antigos inquilinos. 


\section{La casa venduta}

Io sapevo che quei tre venivano a trovarmi perché vendevo la mia casa. Ma, nonostante, fui contento di sentire, dalla mia stanza, che domandavano di me. La serva non voleva farli entrare, voleva dire che non c'ero; ma io aprii la porta; e li salutai con un brivido, nella voce e in tutta la persona. Essi mi risposero ridendo, strizzandosi un occhio; divertendosi della mia sciocchezza. Forse, credevano che non me ne accorgessi né meno: in ogni modo, non se ne curavano. Lo capivo bene. Ma io non intendevo di cambiarmi d'animo. Dissi subito, fregandomi le mani: "Sono venuti per vedere la casa? Hanno fatto bene".

Li condussi, prima, a girare l'appartamento che abitavo io; ch'era il più piccolo. Essi guardavano tutto; si fermavano perfino davanti a un mattone smosso. Uno, il signor Achille, che aveva il bastone, batteva su i muri, per sentire quanto erano grossi. Prendevano in mano gli oggetti che erano sopra i miei mobili, toccavano le tende; un altro, il signor Leandro, s'affacciò a una finestra per sputare. Poi andammo negli altri appartamenti; dove erano i miei pigionali, che m'accoglievano con segni di meraviglia ostile. Ma, poi, perché io ero anche compiacente da fingere di non ascoltare, dicevano male di me con i tre compratori, si mettevano già d'accordo per quando uno di loro sarebbe diventato il padrone. Nessuno mi rispettava; mi lasciavano passare dietro a tutti, stavano a parlare quanto volevano. Ed io guardavo, forse per l'ultima volta, le pareti della mia casa. Poi, non guardavo né meno più: entravo ed escivo come se non sapessi quello che facevo e perché mi trovavo lì.

Quando risalimmo nel mio appartamento, mi disse il terzo che di soprannome si chiamava Piombo:

"Noi abbiamo già perso troppo tempo. Ci dica lei quanto vuole, signor Torquato".

Io volevo spicciarmi, non volevo né meno farmi consigliare da qualcuno. Avrei potuto chiedere diecimila lire, e ne chiesi soltanto ottomila. Ebbi paura che fosse troppo, e che se n'andrebbero senza combinare. Allora il signor Achille mi rimproverò severamente:

"Ma a chi la vuole vendere? Qui siamo in tre". 
Maria Gloria Cusumano Mazzi. La casa venduta, de Federigo Tozzi

Io risposi:

"Credevo che la volessero comprare tutti e tre insieme".

Piombo rispose:

"Io, in vece, non gliene darei né meno tremila".

Ero confuso, e m'arrischiai a dire.

"Non basterebbero per l'ipoteca, che è di settemila lire. Ne ho chieste ottomila, perché almeno mille restino a me." E, sorridendo, arrossii.

"E di che ne vuol fare lei di mille lire?"

"Io... non mi resta altro. Qualche mese mi basteranno."

"Un mese più o uno meno che conta?"

“E' vero" risposi.

"Ma tutti e tre insieme non si può contrattare."

"E' quel che penso anch'io."

"Allora, lei doveva star zitto."

Ma il signore Leandro propose:

"Gliene dò settemila, quante ce ne vogliono per l'ipoteca".

"E a me?"

"Non mi riguarda."

Sentii una gran simpatia verso di lui. Ma gli altri due finsero di essere scontenti: perché avevo già capito che il compratore era uno solo. Gli altri due dovevano soltanto fingere di comprare, offrendo meno di lui. Avevo capito, ma non me ne importava. Anzi, mi offesi che avessero ricorso a quel mezzo come se io da me stesso non fossi stato abbastanza onesto da chiedere quel che bisognava soltanto per l'ipoteca. Perché io non volevo aver niente. Io volevo restare senza niente.

Il vero compratore, il signor Leandro, era un negoziante non so di che; forse di grano. Aveva il viso rosso e i baffi neri. Il signor Achille era un biondino, e Piombo un vecchio con i capelli bianchi. Mentre si discorreva così, dissi alla serva, Tecla, che facesse il caffè per loro e per me. Quelli non ci badarono né meno. E il vero compratore mi disse con impazienza:

"Pochi discorsi: le piace o no? Il caffè lo prendiamo fuori, con i nostri denari". 
Io risposi:

"Ma ho detto che lo facesse perché credevo che gradissero una mia gentilezza. Ho voluto accoglierli come meglio posso".

"Non importa, non importa!"

Allora, il vecchio si mise a dirmi:

“In vece del caffè, poteva darmi il tempo di fare l'offerta. Ma io più di seimila lire non gliele davo".

Il biondino scosse la testa, quasi per compatirli ambedue che fossero così lesti a concedermi tutta quella somma. Pareva che io li avessi messi in mezzo, e mi trovavo così imbarazzato e umiliato che avrei voluto regalare la casa; se non ci fosse stata l'ipoteca da togliere. Mi vergognavo dell'ipoteca, perché appunto non potevo essere libero a modo mio. Il signor Leandro riprese:

"Se sta bene come ho ormai detto, benché ne sia più che pentito, venga oggi dal mio notaio; dove si stenderà il contratto".

Come avrei potuto rifiutare? E perciò, credendo che facesse caso alla mia delicatezza, proposi:

"Se crede, posso venire magari prima di mezzogiorno".

Ma egli se ne offese:

"Ho da fare altre cose, molto più serie di queste!".

Allora, perché non mi parlasse più così bruscamente, risposi:

"Mi scusi perché non lo sapevo".

"Facciamo meno chiacchiere: alle due, non più tardi, si faccia trovare dal mio notaio."

Io ero vergognoso di non sapere il nome del notaio, e osai chiederlo a lui. Mi disse:

"Il notaio Bianchi... Lo sa dove sta?".

"Lo domanderò; per non sbagliare."

Intanto Tecla aveva portato il caffè. Ma siccome non aveva nessun sapore ed era troppo bollito, io non sapevo più che parole inventare: avevo paura che lo trovassero cattivo.

Il signor Achille, il biondino, disse: 
"Ora che ha voluto farci prendere anche il caffè, non dà la senseria a me e a lui?". E accennò, con la punta del bastone, Piombo. Io chiesi, come rientrando in me:

“La senseria?".

"Certo! Crede che siamo venuti per fare una passeggiata?"

"Ma io... non ho un soldo!"

Non sapevo se mi avrebbero perdonato. E infatti il signor Achille alzò il bastone come per darmelo su la testa:

"E allora chi ci pensa a noi?". E mi afferrò per un braccio. Io volevo dire che se la facessero dare dal compratore, ma avevo paura che Piombo mi rispondesse troppo male. Volsi gli occhi attorno; e dissi pallido di commozione:

"Se credono, potrò regalare questa mobilia...".

"C’è soltanto questa?"

Risposi lesto, perché fosse più amabile;

"C'è, di là, il letto. Poi le cazzeruole di rame, in cucina".

"Sono sempre adoprabili?"

"Sono sempre buone." E chiamai la serva perché ne portasse alcune, a fargliele vedere. Piombo, il vecchio, disse:

"Credevo che avremmo fatto un affare meno magro!".

E mi dette un'occhiata di compatimento.

A me si stringeva il cuore; ma che potevo dare ancora? Cercai, con gli occhi, perfino su al soffitto: non c'era proprio più niente.

Bevvero il caffè e mi finirono lo zucchero, mangiandolo a pezzetti. Io, in vece, non avevo né meno empito la tazza; per far vedere che il caffè l'avevo fatto fare soltanto per loro. Ci tenevo che ne fossero certi! Ma non mi fecero né meno un complimento; e Piombo chiese:

"Le tazze ce le mette nella senseria, signor Torquato?".

Il signor Achille gli assestò un colpo sul collo:

"E a chi le deve dare?".

Allora perché il signor Achille si rassicurasse, dissi: 
"Io non le adoprerò più".

Il compratore si puliva il naso con le dita, pensando già ai suoi progetti di come poteva utilizzare la casa; e perciò mi chiese:

"Lei quando me le lascia libere queste stanze?".

Io avevo pensato di trattenermi ancora qualche giorno; ma siccome egli me le chiedeva subito, risposi:

"Oggi stesso... dopo il contratto".

"Va bene, va bene!"

“Mi dispiace di non potergliele lasciare magari prima."

"Poco male!"

$\mathrm{Ma}$, a questo punto, cominciai a sentire come se mi fosse strappato il cuore. Se ne accorsero subito, e il compratore mi chiese con una voce che minacciava:

"S'è pentito, forse?".

Io feci uno sforzo e risposi:

“No, no! Tutt'altro! Pensavo ad un'altra cosa!".

"Non ci mancava che se ne fosse pentito! Siamo uomini, non mica ragazzi! Le sarebbe messo poco conto, però: perché questi due, all'evenienza, potrebbero anche fare da testimoni di quel che abbiamo combinato."

Io dissi:

“Le assicuro che... non ci pensavo né meno a questo!".

"Ormai, se Dio vuole, cosa fatta capo ha." Andò a una parete e disse:

"Domani stesso ci mando il muratore perché ripulisca tutte le stanze e rinforzi gli architravi dove ce ne sarà bisogno. Lo farò salire anche sul tetto perché il pigionale dell'ultimo piano mi ha detto che, da una fessura, quando piove gli sgocciola l'acqua sul pavimento".

“E' vero: c'è una tegola rotta. Non l'ho fatta cambiare io... perché non volevo spendere.

Poi farò scialbare anche la facciata, verniciare le persiane. Mi ci vorrà la spesa di un altro migliaio di lire. Le pare poco?"

Io ammiravo la sua possibilità di fare tutte quelle cose e dissi: 
Maria Gloria Cusumano Mazzi. La casa venduta, de Federigo Tozzi

"Vedrà che bella casa diventa!"

"O che credeva che la lasciassi deperire come ha fatto lei?"

Mi parlava così senza alcun riguardo, con un tono come se io gli avessi fatto qualche cattiva azione. Non mi lasciava né meno pensare, quantunque cercassi tutti i modi di cavargli di bocca una parola con lo stesso sentimento che avevo io. Non so che avrei fatto perché non mi parlasse a quel modo! Ma egli se la pigliava di tutto con me, ed io n'ero molto addolorato; e non mi preoccupavo d'altro. Allora dissi:

"Lascio attaccate anche le fotografie della mia famiglia... perché non so dove portarle... "

"Quelle le può buttar via".

“Le danno noia?"

"O non glielo ho detto che dovrò ripulire tutto?"

Allora si fece dare il bastone dal signor Achille e ne buttò giù quasi una fila; quelle che erano senza cornice. Io avrei voluto raccattarle, ma pensai di aspettare che se ne fossero andati. Volevo, nondimeno, far loro sapere che erano proprio quella di mia madre e della mia sorella morte. Forse avrebbero capito il mio sentimento. Ma non mi arrischiavo, giacché il signor Leandro, ormai padrone, le aveva buttate giù a quel modo. Non volevo fare una cosa che non ero sicuro se facesse piacere. Allora, siccome era restata, un poco più alto, una fotografia di mio padre, dissi:

"Butti giù anche quella!".

Ma egli non pensava a queste sciocchezze, e alzò una spalla. Prese in mano in vece un vecchio vaso da fiori, che io avevo sempre tenuto: era un ricordo della mia sorella. Ma, accortosi che la polvere gli aveva insudiciato le dita, disse:

"Ho fatto male a toccarlo!".

Io gli chiesi:

"Si vuole lavare?".

Ma il signor Leandro si servì del suo fazzoletto, benché gli dispiacesse di sporcarlo. Ora era tutto impaurito che per la sua curiosità gli potesse accadere un'altra cosa simile. E perciò dissi: 
"Se credono, possiamo scendere".

Ma gli altri due domandarono:

"C'è caso che la sua serva si porti via qualche cosa? Badi che lei è ora responsabile di tutta questa roba, che è già nostra".

Io risposi mettendomi una mano sul petto:

"Giuro che non mancherà né meno una briccica!".

"Del resto, per essere più sicuro, ci può dare subito le chiavi. Così la serva si fa escire e noi chiudiamo."

"Giacché hanno sospetto di me, si fa come dicono. Tecla! Esciamo insieme."

La serva, una vecchia vedova, disse:

"E il fagotto dei miei cenci quando me lo dà il tempo di farlo?".

Rispose il compratore:

“Tornerai stasera: t'aprirò io".

"Ma ho da avere anche il salario di questo mese!"

Tutti e tre si misero a ridere, e io mi sentii così imbarazzato che non sapevo quel che dire.

"Ne parleremo fuori."

Disse il signor Achille:

"Sarebbe curiosa che per la serva lei non potesse vendere la casa!"

Io risposi:

“Non capisce niente, e non ha nessuna educazione. Ma escirà con me: ci penso io a farla obbedire".

Poi escimmo tutti e cinque insieme. Tecla fu l'ultima, e chiuse la porta.

M'era rimasto tanto da andare a pranzo, e alle due fui puntualissimo dal notaio. Anzi arrivai prima degli altri. Firmai il contratto scritto in carta bollata; e feci la firma più bella che potessi; benché mi tremasse la mano. Io cercavo di capire se erano contenti di me e se avessi detto qualche cosa che potesse sembrare contrario a come volevo mostrarmi. Aspettavo che mi dicessero se volevano altro da me. Il notaio disse: 
Maria Gloria Cusumano Mazzi. La casa venduta, de Federigo Tozzi

"E' fatto tutto!".

E mise il polverino rosso su la carta bollata. Il signor Leandro mi mandò via, dicendo:

"Può andarsene, signor Torquato!".

Io salutai sempre con rispetto, ma nessuno mi rispose. E non ero ancora giunto alla porta, che già parlavano per conto loro.

Scesi le scale del notaio, come se mi fossi tolto un peso d'addosso. Poi non ricordo più quel che feci e dove passai il resto della giornata. Per la sera non avevo né da mangiare né da dormire, e mi sentivo affranto. Ma facevo di tutto per resistere. Quando fu buio, cominciò a piovere dirottamente. Io, allora, andai a ripararmi sotto le grondaie della mia casa venduta. Ero tanto triste; ma avrei voluto essere contento, almeno come la mattina, perché a quell'ora sapevo che i miei pigionali cenavano, e quelli del quartiere di mezzo avevano l'abitudine di suonare il pianoforte: sempre qualche polca nuova. 


\section{A casa vendida}

Eu sabia que aqueles três vinham me encontrar porque eu estava vendendo minha casa. Mas, apesar disso, fiquei contente de ouvir, do meu quarto, que eles perguntavam por mim. A empregada não queria deixálos entrar, queria dizer que eu não estava; mas abri a porta; e os cumprimentei com um tremor na voz e em todo corpo. Eles responderam rindo, piscando entre si; divertindo-se com meu mau jeito. Talvez pensassem que eu nem tivesse percebido: em todo caso, não se importavam com isso. Eu entendia bem. Mas não pretendia mudar meu ânimo. Disse-lhes em seguida, esfregando as mãos uma na outra:

- Vieram pra ver a casa? Fizeram bem.

Inicialmente levei-os para visitar o apartamento em que eu morava; que era o menor. Eles olhavam tudo; paravam até diante de um azulejo solto. Um deles, o senhor Aquiles, que usava uma bengala, batia nas paredes para ver quanto eram espessas. Eles pegavam os objetos que estavam sobre meus móveis, mexiam nas cortinas; um outro, o senhor Leandro, foi até uma janela para cuspir. Depois fomos aos outros apartamentos; onde estavam meus inquilinos, que me recebiam com ares de surpresa hostil. E como eu havia decidido fingir que não ouviria nada, eles falavam mal de mim para os três compradores, e já entravam em acordo para quando um deles se tornasse o proprietário. Ninguém me respeitava; deixavam-me para trás e falavam quando queriam. E eu olhava, quem sabe pela última vez, as paredes da minha casa. Depois, não olhava mais: entrava e saía como se não soubesse o que fazia e por que estava ali.

Quando voltamos ao meu apartamento, o terceiro comprador, apelidado de Chumbo, me disse:

- Nós já perdemos tempo demais. Diga-me quanto quer, senhor Torquato.

Eu queria acabar logo com aquilo, não queria pedir conselho a ninguém. E poderia ter pedido dez mil liras, e pedi somente oito mil. Tive medo que fosse demais, e que eles fossem embora sem fechar negócio. Então o senhor Aquiles me repreendeu severamente:

- Mas a quem quer vendê-la? Aqui somos três. 
Maria Gloria Cusumano Mazzi. La casa venduta, de Federigo Tozzi

- Pensei que os três juntos quisessem comprá-la.

Chumbo respondeu:

- Eu, pelo contrário, não lhe daria nem três mil.

Eu estava confuso, e me arrisquei a dizer:

- Não bastariam para a hipoteca, que é de sete mil liras. Pedi oito para que me sobrem pelo menos mil liras. E, sorrindo, corei.

- E o que o senhor quer fazer com mil liras?

- Eu... não tenho mais nada. É só para alguns meses.

- É um mês a mais ou a menos que conta?

- É mesmo - respondi.

- Mas com os três juntos não se pode negociar.

- É o que eu também acho.

- Então o senhor devia ficar calado.

Mas o senhor Leandro propôs:

- Eu lhe dou sete mil, o suficiente para a hipoteca.

- E pra mim?

- Isso não é da minha conta.

Senti uma grande simpatia por ele.

Mas os outros dois fingiram descontentamento: porque eu já tinha entendido que o comprador era apenas um. Os outros dois deveriam apenas fingir interesse, oferecendo menos do que ele. Eu tinha entendido, mas não me importava. Pelo contrário, me ofendi que tivessem recorrido a tal artimanha como se, da minha parte, eu já não tivesse sido honesto o bastante para pedir somente o tanto de que precisava para a hipoteca. Porque eu não queria ter nada. Eu queria ficar sem nada.

O verdadeiro comprador, o senhor Leandro, era negociante não sei de quê; talvez de trigo. O senhor Aquiles era um loiro, e Chumbo, um velho de cabelos brancos. Enquanto as coisas iam assim, pedi à empregada Tecla que fizesse um café para eles e para mim. Não deram a mínima. E o verdadeiro comprador me disse com impaciência:

- Sem muita conversa: o senhor quer ou não? O café nós tomamos lá fora com nosso dinheiro. 
Então, respondi:

- Mas eu pedi que ela o fizesse porque pensei que agradeceriam uma gentileza minha. Queria recebê-los da melhor maneira possível.

- Não importa, não importa!

Então, o velho começou a me dizer:

- Ao invés do café, o senhor podia me dar tempo de fazer a oferta. Porém, eu não dava mais do que seis mil.

O loiro balançou a cabeça, como para repreendê-los por terem sido tão rápidos em oferecer toda aquela soma. Parecia que eu os tinha enganado e me encontrava tão embaraçado e humilhado que queria poder dar a casa de presente: não fosse a hipoteca para quitar. Envergonhava-me da hipoteca justamente porque não me deixava livre para agir a meu modo. O senhor Leandro respondeu:

- Se está bem como eu disse, embora já esteja até arrependido, vá hoje ao meu tabelião; onde será redigido contrato.

Pensando que ele se importasse com uma delicadeza minha, propus:

- Se o senhor achar melhor, eu posso chegar até antes do meio-dia.

Mas ele se ofendeu:

- Tenho outras coisas a fazer, muito mais sérias do que estas!

Então, para que ele não me falasse mais tão bruscamente, respondi:

- Me desculpe por eu não saber.

- Chega de conversa: às duas, não mais tarde, encontre-se no meu tabelião.

Estava envergonhado por não saber o nome do tabelião, e ousei perguntar-lhe. Ele me disse:

- O tabelião Bianchi... Sabe onde fica?

- Vou perguntar, para não errar.

Enquanto isso, Tecla havia trazido o café. Mas como não tinha nenhum sabor e era requentado, eu não sabia mais o que dizer: tinha medo que o achassem ruim. 
Maria Gloria Cusumano Mazzi. La casa venduta, de Federigo Tozzi

O senhor Aquiles, o loiro, disse:

- Agora que o senhor fez questão que tomássemos até o café, não vai dar a corretagem pra mim e pra ele? - E indicou Chumbinho com a ponta da bengala. Perguntei, caindo em mim:

- A corretagem?

- Claro! Ou o senhor acha que viemos dar um passeio?

- Mas eu... não tenho um tostão!

Não sabia se me perdoariam. E de fato o senhor Aquiles levantou a bengala como para acertar minha cabeça:

- E então quem pensa em nós? - E me pegou pelo braço. Eu queria dizer que pedissem ao comprador, mas temia que Chumbo me respondesse muito mal. Olhei ao redor, e disse pálido de comoção:

- Se quiserem, posso dar esta mobília...

- Só tem esta?

Respondi logo, para que fosse mais amável:

- Pra lá, tem a cama. E também as panelas de cobre, na cozinha.

- São utilizáveis ainda?

- Sempre podem ser reaproveitadas. E pedi à empregada que trouxesse uma para que a vissem. Chumbo, o velho, disse:

- Pensei que íamos fazer um negócio melhor! - e me dirigiu um olhar de lástima.

O coração me apertava; mas o que mais eu podia dar? Olhei em tudo até no teto: Não tinha mais nada mesmo.

Tomaram o café e acabaram com meu açúcar comendo os torrões.

E eu, que não tinha nem enchido a xícara; para fazê-los verem que o café tinha sido feito só pra eles. Esperava que percebessem! Mas não me deram nem um obrigado; e Chumbo disse:

- As xícaras ficam por conta da corretagem, senhor Torquato?

O senhor Aquiles the deu um cutucão no pescoço.

- E para quem mais ele ia dar?

Então, para que o senhor Aquiles se tranqüilizasse, eu disse: 
- Eu não vou mais usá-las.

O comprador limpava o nariz com os dedos, pensando já nos seus projetos de como utilizar a casa: e por isso me perguntou:

- E o senhor, quando me libera os quartos?

Tinha pensando em ficar por mais alguns dias; mas como ele me perguntou assim de repente, respondi:

- Hoje mesmo... depois do contrato.

- Está bem, está bem!

- Sinto muito não poder desocupá-los ainda antes.

- Já que é assim...

Mas, nesse momento, comecei a sentir como se tivessem me arrancado o coração. Eles logo perceberam, e o comprador me perguntou num tom ameaçador:

- Está arrependido talvez?

Fiz um esforço, e respondi:

- Não, não! Pelo contrário! Estava pensando em outra coisa.

- Só faltava que estivesse arrependido! Somos homens! E não moleques! Senão, o senhor não ia sair bem dessa: se isso acontecesse, os dois aqui poderiam até testemunhar o que nós tínhamos combinado.

Eu disse:

- Garanto que... eu nem estava pensando nisso!

- Agora também, seja o que Deus quiser, o que está feito, está feito.

Foi até uma parede e disse:

- Amanhã mesmo vou mandar o pedreiro para limpar todos os quartos e reforçar as laterais da casa onde for necessário. Vou fazê-lo subir no telhado porque o inquilino do último andar me disse que, quando chove, escorre água por uma rachadura no assoalho.

- É verdade; há uma telha quebrada. Eu não mandei trocar... porque não queria gastar.

- Depois vou mandar pintar também a fachada e envernizar as venezianas. Vai me custar mais umas mil liras. O senhor acha pouco? 
Maria Gloria Cusumano Mazzi. La casa venduta, de Federigo Tozzi

- Vai ver que casa linda fica!

- Ou pensava que eu fosse deixá-la deteriorar como o senhor fez?

Falava assim comigo, sem nenhuma consideração, num tom como se eu lhe tivesse feito algum mal. Não me deixava nem pensar, e por mais que eu tentasse não conseguia tirar de sua boca uma palavra sequer com o mesmo sentimento que eu tinha. Não sei o que teria feito para que não me falasse daquele jeito. Mas ele se aborrecia com tudo que eu dizia, e eu me sentia muito ferido; e não pensava em outra coisa. Então eu disse:

- Vou deixar penduradas as fotografias da minha família... porque não sei para onde levá-las.

- Aquelas o senhor pode jogar fora.

- Elas o aborrecem?

- Mas não lhe disse que vou mandar limpar tudo?

Então, pediu a bengala ao senhor Aquiles e derrubou no chão quase uma fileira: aquelas que estavam sem moldura. Eu queria pegá-las, mas pensei em esperar que fossem embora. Gostaria que ao menos soubessem que eram justamente as fotos de minha mãe e de minha irmã falecidas. Talvez tivessem compreendido o meu sentimento. Mas não me arriscava, já que o senhor Leandro, agora proprietário, tinha jogado as fotos daquele modo. Não queria fazer uma coisa que não tinha certeza se ia agradar. Então, como uma foto de meu pai havia ficado um pouco mais no alto, eu disse:

- Derrube aquela também!

Mas ele não pensava nestas bobagens, levantou os ombros. Ao contrário, pegou um velho vaso de flores que eu conservava sempre comigo: era uma lembrança de minha irmã. Mas, percebendo que o pó havia sujado seus dedos, ele disse:

- Fiz mal em tocá-lo.

Eu lhe disse:

- Quer se lavar?

Mas o senhor Leandro usou o próprio lenço embora lhe desagradasse sujá-lo. Agora estava todo apreensivo que por sua curiosidade lhe pudesse acontecer uma outra coisa semelhante. E por isso ele disse: 
- Se quiserem, podemos descer.

Mas os outros dois me perguntaram:

- Há perigo de sua empregada levar embora alguma coisa? Olha que agora o senhor é responsável por todas estas coisas que já são nossas.

Eu respondi levando a mão ao peito:

- Juro que não vai faltar nem uma bugiganga!

- De resto, para ser mais seguro, o senhor pode nos dar logo as chaves. Assim a empregada sai e nós trancamos.

- Já que desconfiam de mim, que seja. Tecla! Vamos sair agora.

A empregada, uma velha viúva, disse:

- E a trouxa com minhas coisas, quando vai me dar tempo de arrumar?

O comprador respondeu:

- Você volta à tardezinha: eu abro a porta para você.

- Mas eu tenho que receber também o salário deste mês!

Os três começaram a rir, e eu me senti tão embaraçado que não sabia o que fazer.

- Vamos falar disto lá fora.

Disse o senhor Aquiles:

- Seria curioso que por causa da empregada o senhor não pudesse vender a casa!

Respondi:

- Ela não entende nada, e não tem nenhuma educação. Mas vai sair comigo; eu me encarrego de fazê-la obedecer.

Depois saímos juntos, os cinco. Tecla foi a última, e fechou a porta.

Restou-me um tempo para o almoço e às duas em ponto cheguei no cartório do tabelião. Aliás, cheguei primeiro que os outros. Assinei o contrato feito em papel timbrado; e fiz a assinatura mais linda que pude; embora a mão me tremesse. Eu procurava saber se eles estavam contentes comigo e se eu tinha dito alguma coisa que pudesse parecer contrária ao que queria demonstrar. 
Maria Gloria Cusumano Mazzi. La casa venduta, de Federigo Tozzi

Esperava que me dissessem se queriam mais alguma coisa de mim. O tabelião disse:

- Está feito!

E colocou seu carimbo no contrato. O senhor Leandro me mandou sair, dizendo:

- Pode ir embora, senhor Torquato!

Fui saindo e me despedi com o respeito de sempre, mas ninguém me respondeu. E eu ainda nem havia chegado perto da saída, e eles já falavam por conta própria.

Desci as escadas do tabelião, como se me tivesse tirado um peso de cima. Depois não me lembro mais do que fiz e onde passei o resto do dia. À tardezinha não tinha nada para comer e nem onde dormir; e me sentia frustrado. Mas fazia de tudo para resistir. Quando escureceu, começou a chover muito forte. Eu, então, fui me abrigar debaixo do beiral da minha casa vendida. Estava muito triste; mas queria estar contente, ao menos como de manhã, porque àquela hora eu sabia que meus inquilinos estavam jantando, e aqueles do apartamento do meio tinham o hábito de tocar piano: sempre alguma polca nova.

\section{Referência}

BORMIOLI, Mario e PELLEGRINETTI, G. Alfonso. Letture Italiane per Stranieri. Volume Secondo. Verona: Mondadori, 1970, p. 225-230. 